Acta Theriologica $36(1-2): 163$ - 170, 1991.

PL ISSN $0001-7051$

\title{
Scimitar and twisted horncores in domestic goats from the Middle Ages
}

\author{
Henryk KOBRYŃ, Alicja LASOTA-MOSKALEWSKA \\ and Krzysztof ŚWIEŻYŃSKI
}

\begin{abstract}
Kobryń H., Lasota-Moskalewska A. and Świeżyński K. 1991. Scimitar and twisted horncores in domestic goats from the Middle Ages. Acta theriol. 36: 163 - 170.

The shape and size of eighty-nine homcores of domestic goats from medieval Plock have been examined. Scimitar horncores were noted in females while males had the horncores either scimitar or twisted. Scimitar horncores of males did not differ from twisted horncores in the basal circumference and the length, while the horncores of females were smaller. The critical value amounted to $105-110 \mathrm{~mm}$.

Department of Animal Anatomy, Warsaw Agricultural University, Nowoursynowska 166, 02-766 Warsaw, Poland (HK, KS); Institute of Archaeology, Warsaw University, Widok 10, 00-023 Warsaw, Poland (AL-M)

Key words: horncores shape, size, domestic goat, Middle Ages
\end{abstract}

\section{Introduction}

The shape of horns and, to be more exact, the direction of their long axis is treated as the most important feature attesting to the origin of domestic goats (Bogolubski 1968). Such an approach is justified by the fact that in contemporary wild goats the shape of horns clearly differs. For example the bezoar goat (Capra aegagrus Erxleben, 1777) has scimitar horns; their long axis is arched without a spiral twisting. Such horns are also called stright. This species is the most frequently treated as ancestor of domestic goat. The horns of another species treated also as the ancestor - Markhor (Capra falconeri Wagner, 1839) are twisted along the long axis showing even 5 twists in the extreme cases. Bogolubski (1968) reports that the differences in the shape of horns in both forms of goats are observed only in males.

The share of the Markhor in the origin of domestic goat is still the subject of investigation. While studying the origin and evolution of domestic goat on the basis of archaeological material, one must be satisfied only with the horncores. In literature there is no information whether the shape of the horncores reflects exactly the external shape of the horns.

The excavated horncores of domestic goats are both scimitar shaped and twisted up to the screw-like shape. Similar types of horncores shapes can also be in different breeds of contemporary domestic goats. The shapes of horncores of prehistorical goats were described by Zeuner (1963), Epstein (1971) and Bökönyi (1974) as well as some scientists from the beginning of the 20th century (quoted after Bogolubski 1968). However, all those papers report only the presence or absence of horncores of both shapes. An extensive review of different breeds of contemporary goats including the information about the shape of their horns is 
presented by Mason $(1981,1984)$. The author tries to connect the shape of horns with the origin of domestic goat. He believes that the direction of twists characteristic for domestic goat does not agree with that observed in the wild screwhorned goat, although there are some exceptions. This general disagreement, points to the monophyletic origin of domestic goat from the bezoar goat with scimitar horns. The twisting of horns in domestic goat is a feature obtained by mutation and preserved by breeding selection.

Papers describing the shapes of horns and horncores of domestic goats do not present any comparison of the frequency of particular shapes and also do not report numerical shares of scimitar or twisted horns in males and females.

While investigating the differentiation of domestic goats living in the present day area of Poland during the early and later period of the Middle Ages, it has been noted that there were two groups of goats differing in the withers height (Świeżyński et al. 1990). We also had every reason to assume that those goats also differed in the horncore length.

In the present report we ask whether the metric characteristic of horncores is connected with their shape and whether two groups of goats living in the early and later period of the Middle Ages also differed in the shape of the horncores and whether the scimitar and twisted horncores are connected with the sex of the animals.

\section{Material and methods}

The investigated material comprised 89 horncores of goats from the medieval Plock. The horncore shape and sex of snimal were noted. In 78 cases the horncore basel circumference and in 52 cases the length along the greater curvature were measured according to the unified methods by von den Driesch (1976). The scimitar horncores had their long axes arched in one plane (Fig. 1). The long axes of the twisted horncores were of spiral type with the degree of twisting from the base to the apex not exceeding $180^{\circ}$ (Fig. 2). It was impossible to check whether the direction of twisting was clockwise or counter-cloclwise or whether it was identical in both horncores (right and left) because the material comprised mainly horncores chopped off from the skulls. The criterion of the sex of animals was the shape of the cross-section of horncores: ellipsoidal cross-sections were typical for females, triangular like - for males. The other criterion was the presence of the frontal tuber in males.

Scimitar and twisted horncores were counted in males and females. Differences in arithmetical means of horncore measurements were tested with the $t$-Student test. Uni- and bi-modality of distributions were estimated on the normal plot on the basis of comulative distribution function. The normality of distributions were tested by Kolmogorov's test (Góralski 1987).

\section{Results}

Among the males horncores 19 were scimitar and 39 twisted while among females 30 horncores were scimitar and one twisted (Table 1).

Both scimitar and twisted horncores of males showed nearly identical basal circumference (Table 2). The scimitar horncores of females had the basal circumference much smaller that it was observed in males. The variability ranges of the circumferences of male and female horncores adjoined at the level of about $110 \mathrm{~mm}$ (Fig. 3). For females it was the highest measurement while for males the lowest. The circumference of the only one twisted female horncore amounted this value (Table 2). 

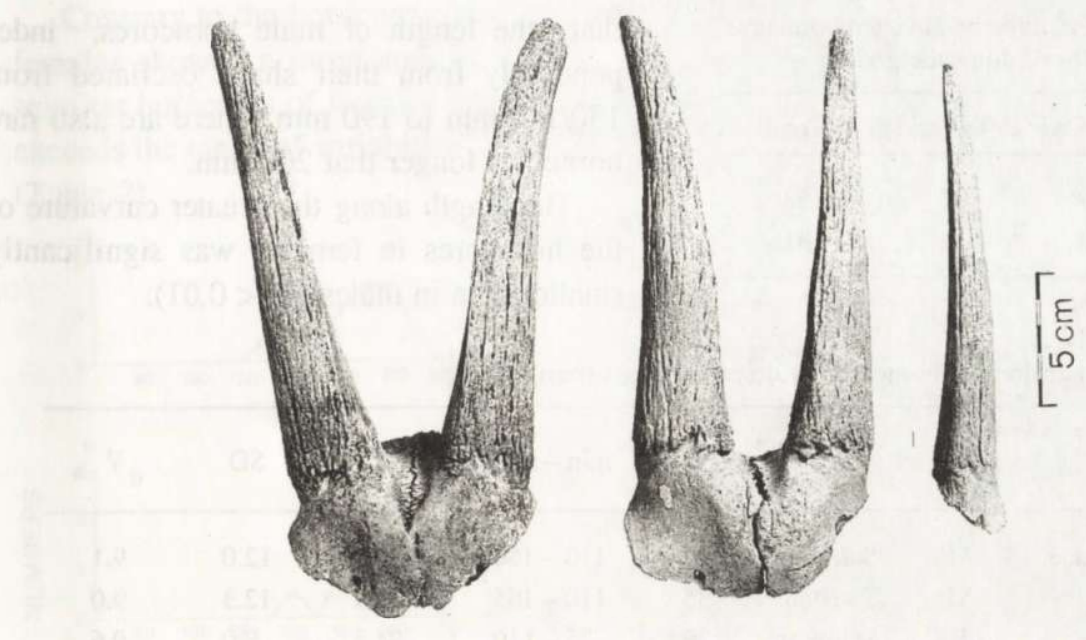

Fig. 1. Scimitar horncores; complete horncores - males, single horncore - female. Fot. M. Dabski.

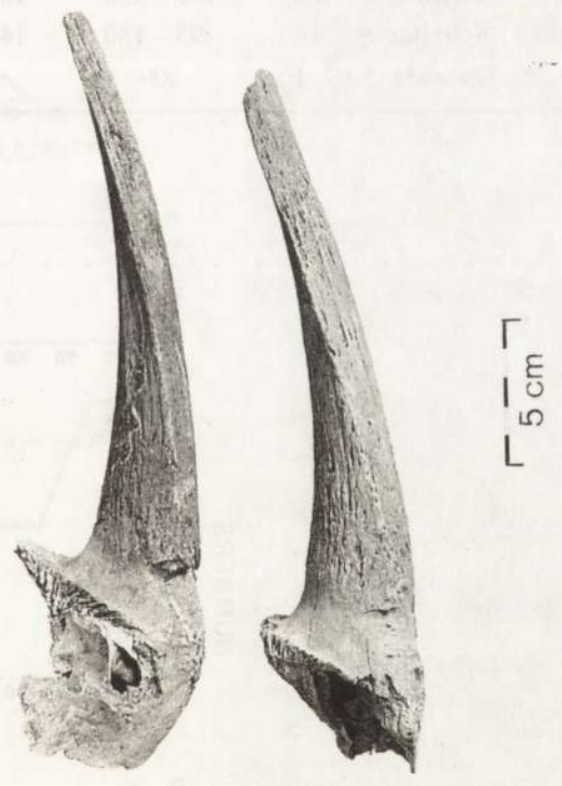

Fig. 2. Twisted horncores - males. Fot. M. Dąbski.

The scimitar horncores of males were a little shorter than the twisted ones, but the difference was not statistically significant $(p>0.05)$. Frequency distribution curves were not clearly unior bi-modal (Fig. 4), but they did not differ from normal distribution $(p>0.05)$. Both cumulative distribution functions changed their course at the level of $200 \mathrm{~mm}$ (Fig. 5). It could be said, 
Table 1. Number of scimitar and twisted horncores of males and females of domestic goats.

\begin{tabular}{lccc}
\hline Sex & Scimitar & Twisted & Total \\
\hline Males & 19 & 39 & 58 \\
Females & 30 & 1 & 31 \\
\hline
\end{tabular}

that the length of male horncores, independently from their shape oscilated from $130 / 140 \mathrm{~mm}$ to $190 \mathrm{~mm}$. There are also rare horncores longer that $200 \mathrm{~mm}$.

The length along the greater curvature of the horncores in females was significantly smaller than in males $(p<0.01)$.

Table 2. Dimensions of homcores of domestic goats (mm).

\begin{tabular}{lccccccc}
\hline Character & Sex & $\begin{array}{c}\text { Horncore } \\
\text { shape }\end{array}$ & $\mathrm{n}$ & $\min -\max$ & $\overline{\mathrm{x}}$ & SD & V \\
\hline Circumference & M & Scimitar & 14 & $110-150$ & 130.9 & 12.0 & 9.1 \\
& M & Twisted & 35 & $110-165$ & 136.9 & 12.3 & 9.0 \\
& F & Scimitar & 29 & $75-110$ & 94.3 & 9.0 & 9.6 \\
Length & F & Twisted & 1 & 110 & - & - & - \\
& M & Scimitar & 14 & $135-230$ & 175.4 & 26.3 & 15.0 \\
& M & Twisted & 20 & $140-250$ & 189.5 & 25.5 & 13.4 \\
& F & Scimitar & 18 & $95-180$ & 140.8 & 22.2 & 15.8 \\
& F & Twisted & 1 & 200 & - & - & - \\
\hline
\end{tabular}

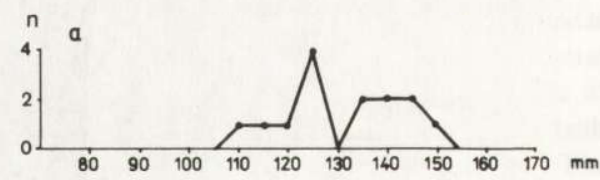

Fig. 3. Frequency distribution of horncore basic circumferences $(\mathrm{a}-$ scimitar horncores of males, b - twisted horncores of males, c - scimitar horncores of females).
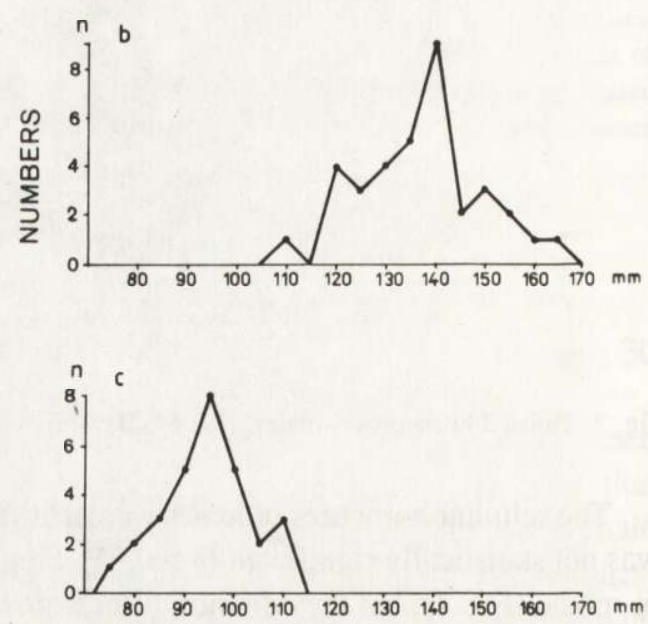
HORNCORE BASIC CIRCUMFERENCE 
Contrary to the horncore circumference, the observed ranges of their lengths in males and females showed a large area of overlapping (Fig. 4). The distribution of the length of the scimitar horncores of females was closer than in males. The only twisted horncore of females exceeds the range of variability for that feature characteristic for scimitar horncores of females (Table 2).
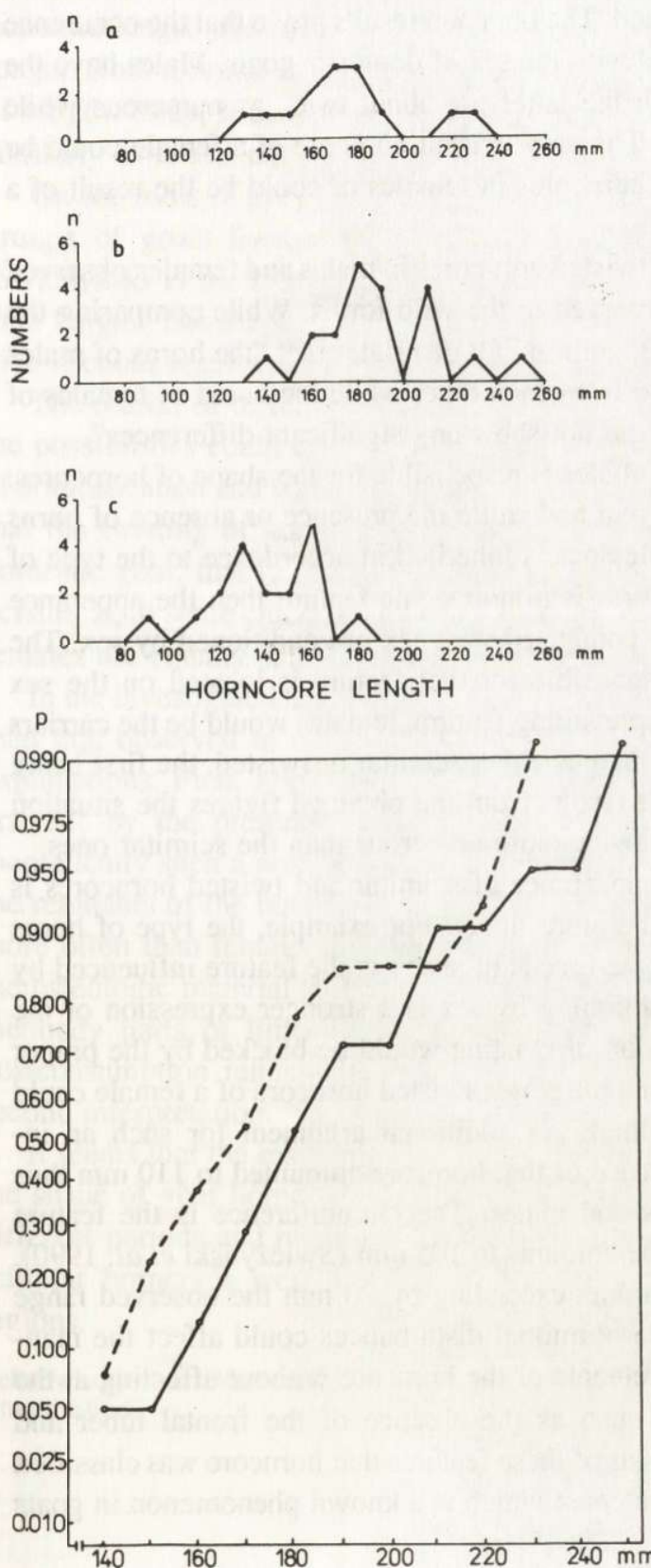

Fig. 4. Frequency distribution of horncore length. See Fig. 3 for explanation.

Fig. 5. Cumulative distribution function of males horncore length on the normal plot (solid line twisted, spoted line - scimitar). 


\section{Discussion}

The studied material originated from one medieval town. Thus it was less differentiated than that collected from many archeological excavations scattered over a larger area. We were interested only in a definite morphological phenomenon and not in a general characterization of domestic goats from a given region and period. The obtained results prove that the occurence of scimitar and twisted horncores is correlated with the sex of domestic goats. Males have the horncores both scimitar and twisted although the latter are about twice as numerous while females have their horncores scimitarshaped. The only twisted horncore of a female could be the extremely rare appearance of the twisted horncores in females or could be the result of a mistake in sex determination.

It seems that the distribution of scimitar or twisted horncores in males and females observed in the present research can agree with that observed in the wild forms. While comparing the shape of horns in bezoar and markhor goats, Bogolubski (1968) states that "the horns of males in the described species of wild bucks differed from each other while the horns of females of both species were comparatively weaker and did not show any significant differences".

We do not know whether only one pair of alleles is responsible for the shape of horncores. Maciejowski and Zięba (1982) report that in goat and cattle the presence or absence of horns depends on one pair of alleles while the hornlessnes is inherited in accordance to the type of Pisum. If we assume that the shape of horncores is a monogenic feature then the apperance of scimitar or twisted horncores can be either connected with sex or conditioned by sex. The connection with sex means that the gene responsible for that feature is located on the sex chromosome X. If the scimitar shape were the prevailing feature, females would be the carriers of that feature while males would have the horncores either scimitar or twisted, the first being more numerous than the latter. However, as it results from the obtained figures the situation is exactly reversed; the twisted horncores are twice more numerous than the scimitar ones.

The other possibility suggesting that the appearance of scimitar and twisted horncores is the feature determined by sex thus seems to be more likely. For example, the type of horns (their weight and the degree of twisting) in some breeds of sheep is the feature influenced by sex (Maciejowski and Zięba 1982). The conditioning by sex is a stronger expression of the same phenomenon. In that case the manifestation of twisting would be blocked by the proper level of female sex hormones. In the light of that the single twisted horncore of a female could result from the hormone disorder in that animal. An additional argument for such an interpretation is the fact that the basal circumference of that horncore amounted to $110 \mathrm{~mm}$ thus reaching the value possible for both females and males. The circumference is the feature strongly diagnostic for sex and the critical value amounts to $105 \mathrm{~mm}$ (Świeżyński et al. 1990). The length of that horncore was also considerable, exceeding by $20 \mathrm{~mm}$ the observed range of scimitar horncores in females. The possible hormonal disturbances could affect the manifestation of twisting and considerable measurements of the horncore without affecting at the same time other features of its morphology such as the absence of the frontal tuber and ellipsoidal shape of the cross-section. On the basis of these features that horncore was classified to the female group. The animal could be an intersex which is a known phenomenon in goats (Haugen 1960, Mason 1981, 1984). 
Variability of horncore basal circumference found in Plock was similar to the samples of early and later medieval goats scattered all around Poland (Świeżyński et al. 1990). Scimitar and twisted horncores of males had nearly identical basal circumference, which proves that this feature is not correlated with the shape of the horncore but only with sex.

In both samples collected from all around Poland and from Plock compared as to the horncore length one could observe two groups: one with shorter horncores and other one with longer. Both scimitar and twisted horncores of males had nearly identical frequency distribution of length. Thus, it can be said, that the shape of horncores is not correlated with the length similarly as it was not correlated with the circumference.

On the basis of the presented material it can be presumed that the earlier distinguished two groups of goats living in Poland during the early and later period of the Middle Ages (Świeżyński et al. 1990) do not differ in the shape of horncores although probably differ in their length. The shape of horncores is correlated only with sex but in a way more complicated than it could result from the rules of a normal statistical correlation.

The reason of differenciation into scimitar and twisted horncores is still not clear. One of the possibilities could be that the feature of the horncore twisting appeared at a certain stage of domestication and was passed down to the progeny. Another opinion is also possible, namely that the twisting of horncores appears as an inherited trait resulting from a mixed origin of domestic goat, that is from a wild bezoar goat and a screwhorned goat, i. e. Markhor. That version is, to same extent, supported by the fact that the horns of both bezoar and screwhorned females are equally scimitar-shaped which can justify the obtained result.

In the investigated material the male and female horncore ratio was $2: 1$ thus being reversed than that observed in our earlier research (Świeżyński et al. 1990). There are two possible explanations. First, hornless goat females could exist in the medieval Pock. It has not been proved by the presence of hornless skulls in the whole material of bony remnants but theoretically such a possibility exists. Second, in the municipal conditions we could deal with the remnants of the butchering trade. It is obvious that male goats would be slughtered much more often than female goats left for breeding in the suburban settlements. While analysing the osteologic material from that site excavation it has been noted that bones connected with the body parts of little culinary attraction were more often present than in usual sets of postconsumption remnants. That atypical anatomical composition of remnants supports the second interpretation.

It seems that the results obtained should encourage the archaeozoologist to note and report the shape of goat horncores. It is possible that in case of collecting numerous material from different periods and regions the answer could be fund to the question whether the shares of scimitar horncores were always constant or whether they changed with time or different regions.

Acknowledgement: We would like to express our gratitude to prof. Tadeusz Sławiński for his checking of genetic interpretation. 


\section{References}

Bogolubski S. 1968. Pochodzenie i ewolucja zwierzat domowych. PWRiL, Warszawa: 1-462.

Bökönyi S. 1974. History of domestic mammals in Central and Eastern Europe. Akadémiai Kiado. Budapest: $1-597$.

Driesch von den A. 1976. A guide to the measurement of animal bones from archaeological sites. Peabody Mus. Bull. 1: 1 - 136.

Epstein H. 1971. The origin of the domestic animals of Africa. Edition Leipzig, Leipzig: 1 - 719.

Góralski A. 1987. Metody opisu i wnioskowania statystycznego w psychologii i pedagogice. PWN, Warszawa: $1-355$.

Haugen E. 1960. L'hermaphrodisme chez chévre. Meldinger Norges Landbrukhogskole 39: 1 - 31.

Maciejowski J. and Zięba J. 1982. Genetyka zwierzat i metody hodowlane. PWRiL, Warszawa: 1 - 326.

Mason I. L. 1981. Wild goat and their domestication. [In: Goat production. C. Gall, ed.]. London, N. York, San Francisco, Sydney: $36-55$.

Mason I. L. 1984. Goat. [In: Evolution of domesticated animals. I. L. Mason, ed.]. London, N. York: 85 - 99.

Świeżyński K., Kobryń H. and Lasota-Moskalewska A. 1990. The size differentiation of the domestic goat (Capra hircus, Linnaeus 1758) at early mediaeval and mediaeval periods in Poland. Anim. Sc. Papers and Reports. [In press]

Zeuner F. E. 1963. A history of domesticated animals. Hutchinson, London: 1 - 560.

Received 7 July 1990, accepted 22 May 1991. 